Syntax Literate: Jurnal Ilmiah Indonesia p-ISSN: 2541-0849

e-ISSN: 2548-1398

Vol. 7, Special Issue No. 1, Januari 2022

\title{
PREVALENSI DISFUNGSI EREKSI PADA PESEPEDA USIA 25-55 TAHUN DI KOTA MEDAN
}

\author{
Muhammad Fahmi Ikram ${ }^{1}$, Syah Mirsya Warli ${ }^{2}$, Fauriski Febrian Prapiska ${ }^{3}$, \\ Dhirajaya Dharma Kadar ${ }^{4}$ \\ ${ }^{1}$ Student of the Faculty of Medicine Universitas Sumatera Utara, Medan \\ ${ }^{2}$ Department of Urology, Universitas Sumatera Utara, Medan \\ ${ }^{3}$ Department of Urology, Universitas Sumatera Utara, Meda \\ ${ }^{4}$ Department of Urology, Universitas Sumatera Utara, Medan \\ Email: fahmipostman21@gmail.com,war_uro@yahoo.com, fauriski@gmail.com, \\ dhira303@yahoo.com
}

\begin{abstract}
Abstrak
Latar belakang. Disfungsi ereksi merupakan penyakit seksual dan menimbulkan dampak yang signifikan dalam mempengaruhi kualitas hidup seorang pria. Disfungsi ereksi sendiri didefinisikan sebagai ketidakmampuan yang konsisten atau berulang untuk mencapai dan / atau mempertahankan ereksi penis yang cukup untuk kepuasan seksual, termasuk kinerja seksual yang memuaskan. Secara global, prevalensi disfungsi ereksi diperkirakan sekitar 3-76,5\%. Eropa merupakan benua dengan prevalensi disfungsi ereksi tertinggi (10-76,5\%), diikuti Asia (8-71,2\%), Oceania (40,3-60,69\%), Afrika (24-58,9\%), Amerika Utara (20,7-57,8), dan yang terendah terdapat di Amerika Selatan (14-55,2). Pada studi yang dilakukan di Kota Jakarta didapati prevalensi disfungsi ereksi di Kota Jakarta pada 255 sampel pria berumur 20-80 tahun sebanyak 36,5\% dengan rincian 22,3\% pada disfungsi ereksi ringan, $13,7 \%$ ringan ke sedang, 3,1\% sedang, dan $0,8 \%$ berat. Faktor-faktor yang dapat menyebabkan disfungsi ereksi bersifat multifaktoral, diantaranya Diabetes Melitus, Hipertensi, peningkatan usia, penyakit jantung, dan penggunaan obatobatan yang mempengaruhi fungsi ereksi. Namun, penurunan aliran darah dan neuropati saraf pudendal karena kompresi di perineum pada saat bersepeda merupakan faktor risiko yang juga dapat menyebabkan gangguan pada fungsi ereksi sehingga berujung pada disfungsi ereksi. Tujuan. Penelitian ini bertujuan untuk mengetahui prevalensi pada pesepeda dengan usia 25-55 di Kota Medan. Metode. Penelitian yang dilakukan bersifat deskriptif dengan desain cross sectional. Sampel pada penelitian ini adalah pesepeda di Kota Medan yang memenuhi kriteria inklusi dan eksklusi. Teknik pengambilan data adalah Consecutive sampling. Hasil. prevalensi DE pada pesepeda usia 25-55 tahun di kota medan sebesar 20\% yang dinilai dengan skoring IIEF-5 pada total sampel 95 pesepeda (100\%). Kesimpulan. terdapat sebesar 20\% kejadian DE pada pesepeda usia 25-55 tahun di kota Medan.
\end{abstract}

Kata kunci: bersepeda; disfungsi ereksi; prevalensi

$\begin{array}{ll}\text { How to cite: } & \text { Ikram. M. F. et al (2022) Prevalensi Disfungsi Ereksi pada Pesepeda Usia 25-55 Tahun di Kota Medan, Syntax } \\ & \text { Literate: Jurnal Ilmiah Indonesia, 7(1). } \\ \text { E-ISSN: } & \text { 2548-1398 } \\ \text { Published by: } & \text { Ridwan Institute }\end{array}$




\section{Abstract}

Background. Erectile dysfunction is a sexual disease and has a significant impact on a man's quality of life. Erectile dysfunction is defined as the consistent or repeated inability to achieve and/or maintain a penile erection sufficient for sexual satisfaction, including satisfactory sexual performance. Globally, the prevalence of erectile dysfunction is estimated at 3-76.5\%. Europe is the continent with the highest prevalence of erectile dysfunction (10-76.5\%), followed by Asia (8-71.2\%), Oceania (40.3-60.69\%), Africa (24-58.9\%), North America (20.7-57.8), and the lowest was in South America (14-55.2). In a study conducted in the city of Jakarta, it was found that the prevalence of erectile dysfunction in the city of Jakarta in 255 samples of men aged 20-80 years was $36.5 \%$ with details of $22.3 \%$ in mild erectile dysfunction, $13.7 \%$ mild to moderate, $3.1 \%$ medium, and $0.8 \%$ by weight. Factors that can cause erectile dysfunction are multifactorial, including diabetes mellitus, hypertension, increasing age, heart disease, and the use of drugs that affect erectile function. However, decreased blood flow and pudendal nerve neuropathy due to compression in the perineum during cycling are risk factors that can also cause erectile dysfunction and lead to erectile dysfunction. Purpose. This study aims to determine the prevalence of cyclists aged 25-55 in the city of Medan. Method. This research is descriptive with a cross sectional design. The sample in this study were cyclists in the city of Medan who met the inclusion and exclusion criteria. The data collection technique is Consecutive sampling. Results. the prevalence of ED in cyclists aged 25-55 years in Medan city was 20\% as assessed by a IIEF-5 score in a total sample of 95 cyclists (100\%). Conclusion. there is a $20 \%$ incidence of ED in cyclists aged 25-55 years in the city of Medan.

Keywords: bicycle; erectile dysfunction; prevalence

\section{Pendahuluan}

Disfungsi Ereksi (DE) dapat dikonseptualisasikan sebagai gangguan dalam fase gairah respons seksual dan didefinisikan sebagai ketidakmampuan yang konsisten atau berulang untuk mencapai dan / atau mempertahankan ereksi penis yang cukup untuk kepuasan seksual, termasuk kinerja seksual yang memuaskan (Burnett et al., 2018). Perhatian tertuju pada dampak yang ditimbulkan oleh disfungsi ereksi terhadap penurunan kualitas hidup pria secara global. Prevalensi Disfungsi ereksi secara global diperkirakan sekitar 3-76,5\% yang telah diukur oleh semua jenis kuesioner dan dikaitkan dengan bertambahnya usia. Penggunaan kuesioner International Index of Erectile Function (IIEF) dan the Massachusetts Male Aging Study (MMAS) mengidentifikasi prevalensi yang tinggi terdapat pria muda ( $<40$ tahun) (Kessler, Sollie, Challacombe, Briggs, \& Van Hemelrijck, 2019).

Hasil yang telah dikumpulkan mengungkapkan bahwa prevalensi tertinggi terdapat di Eropa (10-76,5\%), Asia (8-71,2\%), Oceania (40,3-60,69\%), Afrika (24$58,9 \%$ ), Amerika Utara (20,7-57,8), dan yang terendah adalah Amerika Selatan (1455,2). Ditinjau dari tingkat keparahannya secara global prevalensi tertinggi disfungsi ereksi terdapat pada pasien dengan gejala yang ringan (25,1-36,7\%), diikuti dengan gejala yang sedang $(8,5-25,0 \%)$ hingga gejala yang berat $(1,3-16,77 \%)$ (Kessler et al., 
Muhammad Fahmi Ikram, Syah Mirsya Warli, Fauriski Febrian Prapiska, Dhirajaya Dharma Kadar

2019). Di Indonesia sendiri prevalensi disfungsi ereksi adalah $4 \%$ pada disfungsi ereksi sedang-berat yang diukur dengan kuesioner the Sexual Health Inventory for Men (SHIM) (McMahon, Lee, Park, \& Adaikan, 2012). Pada studi yang juga dilakukan oleh Ponco et al. didapati prevalensi disfungsi ereksi di Kota Jakarta pada 255 sampel pria berumur 20-80 tahun sebanyak 36,5 \% dengan rincian 22,3\% pada disfungsi ereksi ringan, $13,7 \%$ ringan ke sedang, $3,1 \%$ sedang, dan $0,8 \%$ berat (Birowo, Deswanto, \& Rasyid, 2019).

Beberapa faktor risiko dari disfungsi ereksi telah dipaparkan dari beberapa sumber dan referensi. Merokok, obat-obatan, faktor hormonal, riwayat penyakit komorbid (Diabetes Melitus, Hipertensi, Penyakit jantung, penyakit Peyronie), riwayat pembedahan seperti prostatektomi dan reseksi abdominoperineal, dan faktor psikososial seperti depresi merupakan faktor risiko dari terjadinya disfungsi ereksi (Kirby, 2006; Wein, Kavoussi, Partin, \& Peters, 2016).

Kebiasaan bersepeda memang menjadi tren bagi masyarakat di Indonesia dari dulu sampai sekarang, baik karena efek pandemi ataupun dari beberapa mereka yang memang sudah rutin bersepeda. jam terbang tinggi yang dimiliki oleh para pesepeda ini menimbulkan suatu masalah baru terkait faktor risiko di bidang urologi, yaitu disfungsi ereksi. Ditinjau dari frekuensi, intensitas, dan posisi serta jenis sepeda yang mereka gunakan dalam bersepeda, penekanan saraf dan arteri pudendal merupakan suatu mekanisme yang paling mungkin terjadi dalam menyebabkan disfungsi ereksi (Gan et al., 2020). Posisi pesepeda yang bersandar ke depan melawan arcus pubic menyebabkan kompresi saraf pudendal yang berjalan melalui kanal pudendal atau kanal alcock. Kompresi dan neuropati pada saraf pudendal yang terus menerus berimplikasi pada peningkatan kejadian disfungsi ereksi (Gan et al., 2020). Selanjutnya kompresi perineal juga dihubungkan pada insufisiensi arteri penis, dan disfungsi ereksi yang disebabkan oleh disfungsi veno-oklusif (McManus, Connor, Desai, \& Miah, 2020). Insufisiensi suplai darah menyebabkan hipoksemia dan menurunkan perfusi oksigen ke aliran darah penis menyebabkan suatu mekanisme yang kontraproduktif dalam mencapai ereksi, dan dikaitkan dalam penyebab terjadinya disfungsi ereksi (Sommer, Goldstein, \& Korda, 2010).

Dalam studi yang pernah dilakukan, dilaporkan terdapat $16 \%$ pada 160 pesepeda yang mengalami disfungsi ereksi saat melakukan lomba touring sejauh $540 \mathrm{~km}$ (Awad et al., 2018). Namun, gejala disfungsi ereksi yang berlanjut hingga lebih dari seminggu dan lebih dari sebulan hanya $6,9 \%$ dan $1,9 \%$ secara berurut.

Dalam studi Telaah Sistematis dan Meta-Analisis didapati pesepeda mempunyai risiko dua kali lebih besar terkena disfungsi ereksi dari pada yang tidak bersepeda (Gan et al., 2020). Studi tersebut menjadikan umur, skor SHIM dan penyakit komorbid menjadi variabel pengukuran dari penelitian tersebut (Gan et al., 2020).

Penelitian ini bertujuan untuk meneliti dan melihat lebih jauh prevalensi disfungsi ereksi pada pesepeda usia 25-55 tahun yang dilakukan di Kota Medan. 


\section{Metode Penelitian}

Studi ini mengambil pendekatan cross-sectional dan menggunakan desain studi deskriptif. Tujuannya untuk mengetahui prevalensi disfungsi ereksi pada pesepeda berusia 25 hingga 55 tahun di Kota Medan.

Penelitian ini akan dilakukan selama 3 bulan yang dimulai dari Juli hingga September 2021. Lokasi dalam penelitian ini dilaksanakan di beberapa tempat di Kota Medan. Jumlah sampel dalam penelitian ini ditentukan berdasarkan rumus sampel dengan rumus deskriptif kategorik untuk prevalensi yang sebelumnya tidak diketahui:

$$
\mathrm{n}=\frac{z \mathrm{a}^{2} P Q}{d^{2}}
$$

Jumlah sampel yang diperoleh menggunakan rumus ini adalah 95 orang. Teknik ini dilakukan dengan mengumpulkan data pesepeda berusia 25 hingga 55 tahun yang berada di beberapa tempat di Kota Medan.

\section{Hasil dan Pembahasan}

\section{A. Hasil}

Pengumpulan data dilakukan pada bulan Juli sampai dengan Agustus 2021 dengan menggunakan instrumen kuesioner IIEF-5 Questionnaire dan Erectile Hardness Score (EHS) pada target sampel yang memenuhi kriteria inklusi: Laki-laki, sudah menikah, Sexual active, aktif bersepeda (Telah beresepeda selama minimal 6 bulan, dan >2 kali per minggu), usia produktif (25-55 tahun), dan bersedia menjadi objek penelitian. Berikut ini adalah hasil yang dikumpulkan dari responden:

Tabel 1

Distribusi Data Responden Berdasarkan Prevalensi DE Pada Pesepeda

\begin{tabular}{ccc}
\hline Prevalensi & $\mathbf{N}$ & Valid percent (\%) \\
\hline DE & 19 & $20 \%$ \\
\hline $\begin{array}{c}\text { Tidak ada } \\
\text { DE }\end{array}$ & 76 & $80 \%$ \\
\hline Total & 95 & $100 \%$ \\
\hline
\end{tabular}

Berdasarkan tabel 4.1 yang Diukur dengan skoring IIEF-5 Questionnaire, dari total 95 pesepeda (100\%), prevalensi DE terjadi pada 19 pesepeda (20\%) dan Sebanyak 76 pesepeda (80\%) menunjukkan tidak ada DE. Hasil ini sejalan dengan penelitian Awad et al., yang mengungkapkan prevalensi DE pada 160 pesepeda terjadi sebesar $16 \%$. 
Muhammad Fahmi Ikram, Syah Mirsya Warli, Fauriski Febrian Prapiska, Dhirajaya Dharma Kadar

Table 2

Skor EHS Pada Total Responden

\begin{tabular}{lll}
\hline Skor EHS & $\mathbf{N}$ & $\begin{array}{l}\text { Valid } \\
\text { percent } \\
(\boldsymbol{\%})\end{array}$ \\
\hline 1 & 1 & 1 \\
\hline 2 & 0 & 0 \\
\hline 3 & 5 & 5,3 \\
\hline 4 & 88 & 93,7 \\
\hline Total & 95 & 100 \\
\hline
\end{tabular}

Berdasarkan tabel 4.2 untuk skor EHS, dari total 95 pesepeda (100\%), didapati hasil 1 pesepeda (1\%) mempunyai skor 1,5 pesepeda (5,3\%) mempunyai skor 3 dan 88 pesepeda $(93,7 \%)$ mempunyai skor 4 . tidak ada pesepeda $(0 \%)$ yang mempunyai skor 2. Ditinjau dari skor EHS, skor 4 merupakan skor dengan nilai N yang paling banyak pada pesepeda.

Tabel 3

Distribusi Data Prevalensi DE Pada Pesepeda Berdasarkan Derajat Keparahan

\begin{tabular}{llll}
\hline $\begin{array}{l}\text { Derajat } \\
\text { keparahan }\end{array}$ & $\mathbf{N}$ & percent & $\begin{array}{l}\text { Valid } \\
\text { percent }\end{array}$ \\
\hline Tidak ada DE & 76 & 80 & 80 \\
\hline Ringan & 18 & 18,9 & 18,9 \\
\hline $\begin{array}{l}\text { Ringan ke } \\
\text { sedang }\end{array}$ & 0 & 0 & 0 \\
\hline sedang & 0 & 0 & 0 \\
\hline berat & 1 & 1,1 & 1,1 \\
\hline Total & 95 & 100 & 100 \\
\hline
\end{tabular}

Berdasarkan tabel 4.3 yang menunjukkan prevalensi DE pada pesepeda berdasarkan derajat keparahan, didapati dari total 95 pesepeda (100\%), sebanyak 76 pesepeda $(80 \%)$ tidak ada DE, diikuti dengan derajat ringan yaitu sebanyak 18 pesepeda $(18,9 \%)$ dan derajat berat pada 1 pesepeda $(1,1 \%)$. Tidak ada pesepeda yang mengalami DE dengan derajat ringan ke sedang dan sedang (0\%). Ditinjau dari tingkat keparahannya, kejadian paling sering terjadi pada derajat ringan yaitu sebanyak 18 pesepeda dengan prevalensi $18,9 \%$.

Tabel 4

Distribusi Data Prevalensi DE Pada

Pesepeda Berdasarkan Rentang Usia

\begin{tabular}{lll}
\hline $\begin{array}{l}\text { Kelompok } \\
\text { Usia } \\
\text { (Rentang) }\end{array}$ & Kejadian DE (N/\%) & $\begin{array}{l}\text { Total } \\
\text { (N/\%) }\end{array}$ \\
\hline $1(25-30)$ & $1 / 3,4 \%$ & $29 / 100 \%$ \\
\hline $2(31-35)$ & $2 / 9,1 \%$ & $22 /$ \\
& & $100 \%$ \\
\hline
\end{tabular}


Prevalensi Disfungsi Ereksi pada Pesepeda Usia 25-55 Tahun di Kota Medan

\begin{tabular}{lll}
\hline $3(36-40)$ & $3 / 15,8 \%$ & $\begin{array}{l}19 / \\
100 \%\end{array}$ \\
\hline $4(41-45)$ & $3 / 25 \%$ & $12 / 100 \%$ \\
\hline $5(46-50)$ & $9 / 81,8 \%$ & $11 / 100 \%$ \\
\hline $6(51-55)$ & $1 / 50 \%$ & $2 / 100 \%$ \\
\hline Total & $20 / 21,3 \%$ & $95 / 100 \%$ \\
\hline
\end{tabular}

Hasil dari tabel 4.4 mengungkapkan bahwa kejadian DE pada kelompok pesepeda usia 25-30 tahun sebanyak 1 pesepeda $(3,4 \%)$ dari total 29 pesepeda (100\%), untuk kelompok pesepeda usia 31-35 tahun kejadian DE terjadi pada 2 pesepeda $(9,1 \%)$ dari total 22 pesepeda (100\%), pada kelompok pesepeda usia 36-40 kejadian DE terjadi pada 3 pesepeda $(15,8)$ dari total 19 pesepeda $(100 \%)$, diikuti pada kelompok pesepeda usia 41-45 tahun terdapat 3 pesepeda yang mengalami DE (25\%) dari total 12 pesepeda (100\%), pada kelompok pesepeda usia 46-50 tahun sebanyak 9 pesepeda $(81,8)$ mengalami DE dari total 11 pesepeda $(100 \%)$ dan pada kelompok pesepeda usia 51-55 kejadian DE terdapat pada 1 pesepeda (50\%) dari total 2 pesepeda (100\%). Ditinjau dari kelompok usia, prevalensi DE paling sering terjadi pada kelompok usia 46-50 tahun.

Tabel 5

Distribusi Data Prevalensi DE

Pada Pesepeda Berdasarkan Rentang Usia

Terhadap Derajat Keparahan

\begin{tabular}{|c|c|c|c|c|c|c|}
\hline \multirow{2}{*}{$\begin{array}{l}\text { Kelomp } \\
\text { ok usia }\end{array}$} & \multicolumn{5}{|c|}{ Derajat keparahan } & \multirow[t]{2}{*}{ Total (N/\%) } \\
\hline & $\begin{array}{l}\text { Tidak } \\
\text { ada DE } \\
(\mathrm{N} / \%)\end{array}$ & $\begin{array}{l}\text { Rin } \\
\text { gan } \\
(\mathrm{N} / \\
\%)\end{array}$ & $\begin{array}{l}\text { Ringan } \\
\text { ke } \\
\text { sedang } \\
(\mathrm{N} / \%)\end{array}$ & $\begin{array}{ll}\text { in } & \text { Sedan } \\
\mathrm{g} & (\mathrm{N} / \%) \\
\mathrm{g} & \end{array}$ & $\begin{array}{l}\text { Berat } \\
\text { (N/\% } \\
\text { ) }\end{array}$ & \\
\hline $\begin{array}{l}1(25- \\
30)\end{array}$ & $\begin{array}{l}28 / 96,6 \\
\%\end{array}$ & $\begin{array}{l}1 / \\
3,4 \\
\%\end{array}$ & $\begin{array}{ll}0 / 0 & 0 \\
\% & \end{array}$ & $0 / 0 \%$ & $0 / 0 \%$ & $29 / 100 \%$ \\
\hline $\begin{array}{l}2 \\
35)\end{array}$ & $\begin{array}{l}20 / 90,9 \\
\%\end{array}$ & $\begin{array}{l}2 / 9, \\
1 \%\end{array}$ & $\begin{array}{l}0 / 0 \\
\%\end{array}$ & $0 / 0 \%$ & $0 / 0 \%$ & $22 / 100 \%$ \\
\hline $\begin{array}{l}3 \\
40)\end{array}$ & $\begin{array}{l}16 / 84,2 \\
\%\end{array}$ & $\begin{array}{l}3 / 15 \\
, 8 \%\end{array}$ & $\begin{array}{l}0 / 0 \\
\%\end{array}$ & $0 / 0 \%$ & $0 / 0 \%$ & $19 / 100 \%$ \\
\hline $\begin{array}{l}4(41- \\
45)\end{array}$ & $9 / 75 \%$ & $\begin{array}{l}2 / 16 \\
, 7 \%\end{array}$ & $\begin{array}{l}0 / 0 \\
\%\end{array}$ & $0 / 0 \%$ & $\begin{array}{l}1 / 8,3 \\
\%\end{array}$ & $12 / 100 \%$ \\
\hline $\begin{array}{l}5(46- \\
50)\end{array}$ & $2 / 18,2 \%$ & $\begin{array}{l}9 / 81 \\
, 8 \%\end{array}$ & $\begin{array}{l}0 / 0 \\
\%\end{array}$ & $0 / 0 \%$ & $0 / 0 \%$ & $11 / 100 \%$ \\
\hline $\begin{array}{l}6(51- \\
55)\end{array}$ & $1 / 50 \%$ & $\begin{array}{l}1 / 50 \\
\%\end{array}$ & $\begin{array}{l}0 / 0 \\
\%\end{array}$ & $0 / 0 \%$ & $0 / 0 \%$ & $2 / 100 \%$ \\
\hline Total & & $\begin{array}{l}18 / 1 \\
8, \%\end{array}$ & $\begin{array}{l}0 / 0 \\
\%\end{array}$ & $0 / 0 \%$ & $\begin{array}{l}1 / 1,1 \\
\%\end{array}$ & $95 / 100 \%$ \\
\hline
\end{tabular}


Muhammad Fahmi Ikram, Syah Mirsya Warli, Fauriski Febrian Prapiska, Dhirajaya Dharma Kadar

Berdasarkan tabel 4.5 didapati kejadian DE terhadap derajat keparahan pada pesepeda untuk kelompok usia 25-30 dengan total 29 pesepeda (100\%) sebanyak 28 pesepeda $(96,6 \%)$ tidak ada DE, dan 1 pesepeda $(3,4 \%)$ mengalami DE ringan, untuk kelompok usia 31-35 dengan total 22 pesepeda (100\%) sebanyak 20 pesepeda (90,9\%) tidak ada DE, dan 2 pesepeda mengalami DE ringan $(9,1 \%)$, untuk kelompok usia 36-40 dengan total 19 pesepeda (100\%) sebanyak 16 pesepeda $(84,2 \%)$ tidak ada DE dan 3 pesepeda $(15,8 \%)$ mengalami DE ringan, untuk kelompok usia 41-45 tahun dengan total 12 pesepeda (100\%) didapati sebanyak 9 pesepeda $(75 \%)$ tidak ada DE, 2 pesepeda $(16,7 \%)$ mengalami DE ringan, dan 1 pesepeda $(8,3 \%)$ mengalami DE berat, untuk kelompok usia 46-50 tahun dengan total 11 pesepeda (100\%) didapati sebanyak 2 pesepeda $(18,2 \%)$ tidak ada DE, diikuti dengan 9 pesepeda $(81,8 \%)$ mengalami DE ringan dan yang terakhir untuk kelompok usia 51-55 tahun dengan total 2 pesepeda (100\%) sebanyak 1 pesepeda (50\%) tidak ada DE, dan 1 pesepeda lainnya (50\%) mengalami DE ringan. Ditinjau berdasarkan rentang usia terhadap derajat keparahan, kejadian DE cukup banyak pada rentang usia 46-50 tahun yaitu sebanyak 9 pesepeda mengalami DE derajat ringan dengan prevalensi sebesar $81,8 \%$. Adapun hal yang perlu diperhatikan pada DE derajat berat yang terjadi pada 1 pesepeda $(8,3 \%)$ di rentang usia $41-45$ tahun yang mempunyai hasil sejalan dengan penelitian Huang, Munarriz and Goldstein, dimana prevalensi DE sebesar 4,21\% pada derajat berat pada 783 pesepeda dengan rata-rata umur 44 tahun di klub sepeda lokal Kota Boston.

Tabel 6

Distribusi Data Prevalensi DE Pada Pesepeda Berdasarkan Frekuensi Bersepeda Terhadap Derajat Keparahan

\begin{tabular}{lllllll}
\hline $\begin{array}{l}\text { Kelompok } \\
\text { rentang } \\
\text { frekuensi } \\
\text { bersepeda } \\
\text { (kali/minggu) }\end{array}$ & $\begin{array}{l}\text { Tidak } \\
\text { ada DE }\left(\begin{array}{l}\text { N/\%) } \\
\right.$\cline { 2 - 6 }\end{array}\end{array} & $\begin{array}{l}\text { Ringan } \\
\text { N/\%) }\end{array}$ & $\begin{array}{l}\text { Ringan } \\
\text { ke } \\
\text { sedang } \\
(\mathbf{N} / \%)\end{array}$ & $\begin{array}{l}\text { Sedang } \\
(\mathbf{N} / \%)\end{array}$ & $\begin{array}{l}\text { Berat } \\
\left(\begin{array}{l}\text { N/\%) } \\
\text { N/\%) }\end{array}\right.\end{array}$ \\
\hline 3 & $67 / 83,8 \%$ & $12 / 15 \%$ & $0 / 0 \%$ & $0 / 0 \%$ & $1 / 1,2 \%$ & $80 / 100 \%$ \\
\hline 4 & $8 / 61,5 \%$ & $5 / 38,5 \%$ & $0 / 0 \%$ & $0 / 0 \%$ & $0 / 0 \%$ & $13 / 100 \%$ \\
\hline 5 & $1 / 50 \%$ & $1 / 50 \%$ & $0 / 0 \%$ & $0 / 0 \%$ & $0 / 0 \%$ & $2 / 100 \%$ \\
\hline Total & $76 / 80 \%$ & $18 / 18,9 \%$ & $0 / 0 \%$ & $0 / 0 \%$ & $1 / 1,1 \%$ & $95 / 100 \%$ \\
\hline
\end{tabular}

Berdasarkan tabel 4.7 kejadian DE berdasarkan frekuensi bersepeda terhadap derajat keparahan didapati pada frekuensi 3 kali per minggu dengan total 80 pesepeda (100\%) sebanyak 67 pespeda $(83,8 \%)$ tidak ada DE, 12 pesepeda (15\%) dengan DE ringan dan 1 pesepeda (1,2\%) dengan DE berat, lalu pada frekuensi 4 kali per minggu dengan total 13 pesepeda $(100 \%)$ didapati sebanyak 8 pesepeda $(61,5 \%)$ tidak ada DE dan 5 pesepeda mengalami DE ringan $(38,5)$ dan pada frekuensi 5 kali per minggu dengan total 2 pesepeda (100\%) didapati 1 pesepeda $(50 \%)$ tidak ada DE dan 1 pesepeda lainnya (50\%) mengalami DE ringan. Ditinjau dari frekuensi 
bersepeda, prevalensi DE paling sering terjadi pada kelompok dengan frekuensi 3 kali /minggu.

Tabel 7

Distribusi Data Prevalensi DE Pada Pesepeda Berdasarkan Jarak Bersepeda Terhadap Derajat Keparahan

\begin{tabular}{lllllll}
\hline $\begin{array}{l}\text { Kelompok } \\
\text { rentang } \\
\text { jarak } \\
\text { bersepeda } \\
(\mathbf{K m})\end{array}$ & $\begin{array}{l}\text { Tidak } \\
\text { ada DE } \\
(\mathbf{N} / \%)\end{array}$ & $\begin{array}{l}\text { Ringan } \\
(\mathbf{N} / \%)\end{array}$ & $\begin{array}{l}\text { Ringan } \\
\text { ke } \\
\text { sedang } \\
\mathbf{N} / \%)\end{array}$ & $\begin{array}{l}\text { Sedang } \\
(\mathbf{N} / \%)\end{array}$ & $\begin{array}{l}\text { Total } \\
(\mathbf{N} / \%)\end{array}$ & \\
\hline $1(15-20)$ & $7 / 70 \%$ & $3 / 30 \%$ & $0 / 0 \%$ & $0 / 0 \%$ & $0 / 0 \%$ & $10 / 100 \%$ \\
\hline $2(21-25)$ & $9 / 90 \%$ & $1 / 10 \%$ & $0 / 0 \%$ & $0 / 0 \%$ & $0 / 0 \%$ & $10 / 100 \%$ \\
\hline $3(26-30)$ & $23 / 76,7 \%$ & $6 / 20 \%$ & $0 / 0 \%$ & $0 / 0 \%$ & $1 / 3,3 \%$ & $30 / 100 \%$ \\
\hline $4(31-35)$ & $17 / 77,3 \%$ & $5 / 22,7 \%$ & $0 / 0 \%$ & $0 / 0 \%$ & $0 / 0 \%$ & $22 / 100 \%$ \\
\hline $5(36-40)$ & $12 / 92,3 \%$ & $1 / 7,7 \%$ & $0 / 0 \%$ & $0 / 0 \%$ & $0 / 0 \%$ & $13 / 100 \%$ \\
\hline $6(41-45)$ & $7 / 100 \%$ & $0 / 0 \%$ & $0 / 0 \%$ & $0 / 0 \%$ & $0 / 0 \%$ & $7 / 100 \%$ \\
\hline $7(46-50)$ & $1 / 33,3 \%$ & $2 / 66,7 \%$ & $0 / 0 \%$ & $0 / 0 \%$ & $0 / 0 \%$ & $3 / 100 \%$ \\
\hline Total & $76 / 80 \%$ & $18 / 18,9 \%$ & $0 / 0 \%$ & $0 / 0 \%$ & $1 / 1,1 \%$ & $95 / 100 \%$ \\
\hline
\end{tabular}

Berdasarkan tabel 4.8 kejadian DE berdasarkan jarak bersepeda terhadap derajat keparahan didapati pada kelompok jarak 15-20 Km dengan total 10 pesepeda (100\%) sebanyak 7 pesepeda (70\%) tidak ada DE dan 3 pesepeda (30\%) mengalami DE ringan, untuk kelompok jarak 21-25 Km dengan total 10 pesepeda (100\%) ditemukan sebanyak 9 pesepeda (90\%) tidak ada DE dan 1 pesepeda (10\%) mengalami DE ringan, dilanjutkan dengan kelompok jarak 26-30 Km dengan total 30 pesepeda $(100 \%)$ didapati sebanyak 23 pesepeda $(76,7 \%)$ tidak ada DE, 6 pesepeda $(20 \%)$ mengalami DE ringan, dan 1 pesepeda $(3,3 \%)$ mengalami DE berat, lalu pada kelompok 31-35 dengan total 22 pesepeda (100\%) didapati sebanyak 17 pesepeda $(77,3)$ tidak ada DE, 5 pesepeda $(22,7 \%)$ menagalami DE ringan, selanjutnya pada kelompok jarak 36-40 Km dengan total 13 pesepeda (100\%) didapati sebanyak 12 pesepeda $(92,3 \%)$ tidak ada DE, dan 1 pesepeda $(7,7 \%)$ mengalami DE ringan, untuk kelompok jarak 41-45 Km dengan total 7 pesepeda (100\%) ditemukan 7 pesepeda (100\%) tidak ada DE, dan yang terakhir pada kelompok jarak 46-50 Km denga total 3 pesepeda (100\%) ditemukan 1 pesepeda $(33,3 \%)$ tidak ada DE dan 2 pesepeda lainnya $(66,7 \%)$ mengalami DE ringan. Ditinjau dari jarak bersepeda, prevalensi DE paling sering terjadi pada kelompok dengan jarak 26-30 Km.

\section{B. Pembahasan}

Berdasarkan hasil analisa deskriptif menggunakan frequncies dan cross tabulation didapati prevalensi DE pada pesepeda yang dijabarkan melalui beberapa kategori. Prevalensi DE ditinjau secara umum pada pesepeda berumur 25 sampai 55 tahun menunjukkan sebesar $20 \%$ yaitu sebanyak 19 pesepeda dari total 95 total responden $(100 \%)$ yang memenuhi kriteria penelitian. Hasil yang didapat didukung 
Muhammad Fahmi Ikram, Syah Mirsya Warli, Fauriski Febrian Prapiska, Dhirajaya Dharma Kadar

juga oleh penelitian yang dilakukan oleh Awad et al., yang mengungkapkan prevalensi DE pada 160 pesepeda terjadi sebesar 16\%. Manfaat dari penelitian ini adalah:

1. Bagi penelitian, Penelitian ini dapat menjadi referensi dan menjadi pemicu bagi penelitian-penelitian berikutnya yang berhubungan dengan prevalensi disfungsi ereksi pada pesepeda.

2. Bagi pendidikan, Menjadi sarana pembelajaran dalam dunia pendidikan baik kepada para pembaca

3. Bagi peneliti: Penelitian menjadi kesempatan bagi peneliti untuk dapat menambah wawasan dan pengetahuan mengenai tingkat kejadian atau prevalensi disfungsi ereksi pada pesepeda serta sebagai sarana melatih diri dan keterampilan dalam melakukan penelitian.

4. Bagi masyarakat: Dapat menjadi informasi yang bertujuan untuk meningkatkan pengetahuan masyarakat terhadap kejadian disfungsi ereksi pada pesepeda

\section{Kesimpulan}

Prevalensi DE secara umum pada pesepeda ditunjukkan sebanyak 19 pesepeda (20\%) dari 95 total responden (100\%) yang memenuhi kriteria penelitian. 


\section{BIBLIOGRAFI}

Awad, Mohannad A., Gaither, Thomas W., Murphy, Gregory P., Chumnarnsongkhroh, Thanabhudee, Metzler, Ian, Sanford, Thomas, Sutcliffe, Siobhan, Eisenberg, Michael L., Carroll, Peter R., \& Osterberg, E. Charles. (2018). Cycling, and male sexual and urinary function: results from a large, multinational, cross-sectional study. The Journal of Urology, 199(3), 798-804. Google Scholar

Birowo, Ponco, Deswanto, Isaac Ardianson, \& Rasyid, Nur. (2019). Epidemiology of erectile dysfunction: A cross-sectional web-based survey conducted in an Indonesian national referral hospital [version 1; peer review: 1 approved with reservations]. Flo00Research, $\quad 8, \quad 1-11$. https://doi.org/10.12688/F1000RESEARCH.18930.1. Google Scholar

Burnett, Arthur L., Nehra, Ajay, Breau, Rodney H., Culkin, Daniel J., Faraday, Martha M., Hakim, Lawrence S., Heidelbaugh, Joel, Khera, Mohit, McVary, Kevin T., Miner, Martin M., Nelson, Christian J., Sadeghi-Nejad, Hossein, Seftel, Allen D., \& Shindel, Alan W. (2018). Erectile Dysfunction: AUA Guideline. Journal of Urology, 200(3), 633-641. https://doi.org/10.1016/j.juro.2018.05.004. Google Scholar

Gan, Zoe S., Ehlers, Mark E., Lin, Feng Chang, Wright, Sarah T., Figler, Bradley D., \& Coward, R. Matthew. (2020). Systematic Review and Meta-Analysis of Cycling and Erectile Dysfunction. Sexual Medicine Reviews. https://doi.org/10.1016/j.sxmr.2020.01.002. Google Scholar

Kessler, Anna, Sollie, Sam, Challacombe, Ben, Briggs, Karen, \& Van Hemelrijck, Mieke. (2019). The global prevalence of erectile dysfunction: a review. BJU International, 124(4), 587-599. https://doi.org/10.1111/bju.14813. Google Scholar

Kirby, Roger S. (2006). Atlas of Erectile Dysfunction (Second Edi). San Francisco: The Parthenon Publishing Group. Google Scholar

McMahon, C. G., Lee, G., Park, J. K., \& Adaikan, P. G. (2012). Premature Ejaculation and Erectile Dysfunction Prevalence and Attitudes in the Asia-Pacific Region. Journal of Sexual Medicine, 9(2), 454-465. https://doi.org/10.1111/j.17436109.2011.02507.x. Google Scholar

McManus, Alistair, Connor, Martin J., Desai, Ankit, \& Miah, Saiful. (2020). The Hard Truth Regarding Cycling and Erectile Dysfunction? Sexual Medicine Reviews, 8(4), 635-636. https://doi.org/10.1016/j.sxmr.2020.08.001. Google Scholar

Sommer, Frank, Goldstein, Irwin, \& Korda, Joanna Beate. (2010). Bicycle Riding and Erectile Dysfunction: A Review. Journal of Sexual Medicine, 7(7), 2346-2358. https://doi.org/10.1111/j.1743-6109.2009.01664.x. Google Scholar 
Muhammad Fahmi Ikram, Syah Mirsya Warli, Fauriski Febrian Prapiska, Dhirajaya Dharma Kadar

Wein, Alan J., Kavoussi, Louis, Partin, Alan W., \& Peters, Craig A. (2016). CampbellWalsh Urology Eleventh Edition (Eleventh e). Philadelphia: Elsevier. Google Scholar

\section{Copyright holder:}

Muhammad Fahmi Ikram, Syah Mirsya Warli, Fauriski Febrian Prapiska, Dhirajaya Dharma Kadar (2022)

\section{First publication right:}

Syntax Literate: Jurnal Ilmiah Indonesia

This article is licensed under:

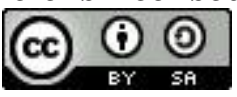

